\title{
Mechanical performance and thermal shock resistance of alumina composites fabricated by temperature gradient spark plasma sintering
}

Junlong Sun

Ludong University

Wansheng Zhao

Ludong University

Rui Zhang

Ludong University

Liu Changxia ( $\square$ liuchangxia2013@163.com )

Columbia University https://orcid.org/0000-0001-5102-270X

\section{Research Article}

Keywords: Thermal shock resistance, Spark plasma sintering, Temperature gradient, Tremolite, Alumina

Posted Date: July 24th, 2020

DOI: https://doi.org/10.21203/rs.3.rs-44210/v1

License: @ (i) This work is licensed under a Creative Commons Attribution 4.0 International License. Read Full License 


\section{Abstract}

Temperature gradient spark plasma sintering technology (TGSPS) was used to fabricate alumina composites with addition of tremolite. The mathematics model of TGSPS was established using piecewise interpolation spline function. Liquid phase sintering took place in the sintering process. Vickers hardness, fracture toughness and flexural strength of the composites were measured. Microstructure observations on fracture surfaces of alumina composites were analyzed. Thermal shock resistance of alumina composites was investigated by measuring the strength retention after varying the temperature difference through the water-quench method. Results showed that the addition of tremolite could promote the liquid phases sintering of alumina composites, decrease the porosity, strength the grain boundaries, improve the mechanical properties, and thus contribute to the improvement in TSR of alumina composites.

\section{Introduction}

Recently, alumina ceramic composites have been receiving growing attention owing to their sound mechanical performances such as high hardness, good chemical inertness, high wear resistance, and so on. High-quality alumina ceramic bodies are widely used for casting hollow turbine blades in aircraft engines and gas turbines [1], ceramic cutting tools for machining hard materials [2, 3], ceramic nozzles in sand blasting treatments[4, 5], Spark plugs[6], coatings[7-9], bearings [10, 11] and dental materials[12]. It is well known that the addition of $\mathrm{CaO}$ could cause alumina to crystallize at low temperature and promote the sintering process [13]. Meanwhile, the addition of small amounts of $\mathrm{MgO}$ suppresses abnormal grain growth of alumina, induce liquid-phase sintering and promote enhanced densification rate [14-20], so fine microstructures and good mechanical properties of alumina ceramic composites can be obtained if $\mathrm{MgO}$ is introduced with appropriate content. It has been reported in reference [21] that, the smaller the sizes of particles are, the lower the temperature to sinter alumina will be. Being composed of $\mathrm{SiO}_{2}, \mathrm{CaO}$ and $\mathrm{MgO}$ phases, tremolite $\left(\mathrm{Ca}_{2} \mathrm{Mg}_{5} \mathrm{Si}_{8} \mathrm{O}_{22}(\mathrm{OH})_{2}\right)$, which is a member in amphibole groupwhich and can be formed by the conversion of dolomite, silica and water together with calcite and carbon dioxide[22], is expected to decrease the sintering temperature of alumina ceramic materials.

Spark plasma sintering (SPS) has the characteristics of fast rising and cooling, low sintering temperature and short holding time, which can reduce the abnormal growth of particles [23-25]. It is possible to achieve high densification $\mathrm{Al}_{2} \mathrm{O}_{3}$ composite prepared by SPS at low temperature, which suppresses its grain growth [26-28]. The densification of $\mathrm{Al}_{2} \mathrm{O}_{3}-\mathrm{YSZ}^{-}-\mathrm{TiO}_{2}$ composites sintered by SPS at temperature of $1350-1400{ }^{\circ} \mathrm{C}$ was higher than $99.2 \%$ [28]. The average grain size of $\mathrm{Al}_{2} \mathrm{O}_{3} / \mathrm{WC}$ composite fabricated by SPS was 1-1.5 $\mu \mathrm{m}$ [29]. The hardness and flexural strength of $\mathrm{Al}_{2} \mathrm{O}_{3}$-Ni nano composites fabricated by SPS at $1573 \mathrm{~K}$ reached $20.5 \mathrm{GPa}$ and $170 \mathrm{MPa}$ [27]. The effect of grain refining can be achieved with the help of SPS approach. Nano-structured alumina composite was prepared from micro-sized powders sintered by SPS at 1200 and $1300{ }^{\circ} \mathrm{C}$ when the starting powder was $3 \mu \mathrm{m}$ [30]. 
Thermal shock resistance (TSR) is one of a major topic for the application of alumina composites in the high-temperature environment. The TSR has been investigated by various researchers for better understanding the mechanisms of improving TSR of $\mathrm{Al}_{2} \mathrm{O}_{3}$ composites [31-35]. The improved TSR of $\mathrm{Al}_{2} \mathrm{O}_{3}-\mathrm{SiC}_{\mathrm{W}}$ composites were achieved by enhancing its densification and the content of yttrium aluminum garner, producing of tabular alumina [31]. The TSR of laminated $\mathrm{Al}_{2} \mathrm{O}_{3} / \mathrm{Mo}-\mathrm{Al}_{2} \mathrm{O}_{3}$ composites was improved by introducing heat-resistant particles into weak layers and improving the interfacial bonding strength of the two layers [32]. The effect of different additives on TSR of $\mathrm{Al}_{2} \mathrm{O}_{3}$ composites is various, and some additives can decrease the TSR of $\mathrm{Al}_{2} \mathrm{O}_{3}$ composites. The TSR of porous $\mathrm{Al}_{2} \mathrm{O}_{3}$ composites was enhanced by introducing $\mathrm{SiC}$ nano powder, while the TSR of the samples with microsized $\mathrm{SiO}_{2}$ was slightly lower than that of unmodified porous $\mathrm{Al}_{2} \mathrm{O}_{3}$ ceramics [33]. The TSR of $\mathrm{Al}_{2} \mathrm{O}_{3}$ composites was sensitive to quenching treatment, however the loss of strength was gradual when $\mathrm{Al}_{2} \mathrm{O}_{3}$ $\mathrm{Er}_{3} \mathrm{Al}_{5} \mathrm{O}_{12}$ composite was quenched in boiling water [34]. There are many factors influencing the TSR of ceramic composite, including mechanical properties and thermal physical parameters, thermal expansion coefficient, etc.[36]. The TSR of laminated $\mathrm{Al}_{2} \mathrm{O}_{3}$ composites could be characterised by the method of macro features (displacement and residual strength) and micro features (crack growth resistance and fracture mode) [35], which provided the comprehensive understanding of the TSR of $\mathrm{Al}_{2} \mathrm{O}_{3}$ composites.

Accordingly, much effort has been made to prepare alumina composites using various technologies mentioned from the above, however, so far the effect of tremolite on the thermal shock behavior of alumina composites, fabricated by TGSPS, is very limited. In this paper, TGSPS was used to fabricate the alumina composites. TGSPS was expected to enhance the densification of alumina composites by avoiding heating too fast compared with the traditional SPS technology. The effects of the tremolite on the mechanical properties, microstructures and TSR of the composites were investigated. The results could contribute to developing a new approach to fabricate alumina composites with good TSR and mechanical properties.

\section{Experimental Procedure}

\subsection{Preparation of the composites}

a- $-\mathrm{Al}_{2} \mathrm{O}_{3}$ of high purity $(99.9 \%)$ and small grain size $(0.5 \sim 1 \mu \mathrm{m})$, produced by Zibo Lucky Star Ceramic Company, Shandong province, China, was used as the starting material. Tremolite with grain size of $1 \sim$ $2 \mu \mathrm{m}$ and composed of $\mathrm{SiO}_{2}$ (59.8 wt.\%), $\mathrm{CaO}(14.7 \mathrm{wt} . \%)$ and $\mathrm{MgO}$ (25.5 wt.\%) was used as the additive. Powders of commercial a- $\mathrm{Al}_{2} \mathrm{O}_{3}$ and tremolite were mixed thoroughly in proper mass proportions, as listed in Table 1, and milled with alumina balls for $90-100 \mathrm{~h}$ in an alcohol medium to obtain a homogeneous mixture. The ball to powder mass ratio is 3 to 1 and that of alcohol to powder is 2 to 1 . The mixture was dried in vacuum and screened. And then placed in a graphite die using the technology of TGSPS at temperature of $1350^{\circ} \mathrm{C}$ with pressure of $35 \mathrm{MPa}$ for $5 \mathrm{~min}$. 
Table 1

Compositions and mechanical properties of TGSPS sintered alumina composites

\begin{tabular}{|llllll|}
\hline Sample & $\begin{array}{l}\text { Compositions } \\
\text { (wt.\%) }\end{array}$ & $\begin{array}{l}\text { Relatively } \\
\text { density(\%) }\end{array}$ & $\begin{array}{l}\text { Vickers } \\
\text { hardness } \\
(\mathrm{GPa})\end{array}$ & $\begin{array}{l}\text { Fracture toughness } \\
\left(\mathrm{MPa} \cdot \mathbf{m}^{1 / 2}\right)\end{array}$ & $\begin{array}{l}\text { Flexural } \\
\text { strength } \\
\text { (MPa) }\end{array}$ \\
\hline PAO & $\begin{array}{l}100 \% \mathrm{Al}_{2} \mathrm{O}_{3} \\
\text { AOT2 }\end{array}$ & 98.5 & $17.6 \pm 1.0$ & $4.65 \pm 0.2$ & $391.6 \pm 15$ \\
\hline AOT4 & $\begin{array}{l}98 \% 100+2 \% \\
\text { tremolite }\end{array}$ & 98.6 & $18.3 \pm 1.5$ & $4.50 \pm 0.3$ & $416.3 \pm 12$ \\
\hline $\begin{array}{l}96 \% 100+4 \% \\
\text { tremolite }\end{array}$ & 99.2 & $20.1 \pm 1.3$ & $4.77 \pm 0.4$ & $503.5 \pm 18$ \\
\hline AOT6 & $\begin{array}{l}94 \% 100+6 \% \\
\text { tremolite }\end{array}$ & 99.3 & $18.4 \pm 1.1$ & $4.15 \pm 0.1$ & $538.2 \pm 10$ \\
\hline
\end{tabular}

Table 2

TGSPS sintering process ( $30 \mathrm{~min})$

\begin{tabular}{|c|c|c|c|c|c|c|c|}
\hline Temperature & $20-$ & 700- & 1000 & 1350 & $1350-$ & $1000-$ & 50 \\
\hline$\left[{ }^{\circ} \mathrm{C}\right]$ & 700 & 1000 & 1350 & & 1000 & 50 & \\
\hline $\begin{array}{l}\text { Speed of heating up and cooling } \\
{\left[{ }^{\circ} \mathrm{C} / \mathrm{h}\right]}\end{array}$ & 150 & 80 & 60 & $\begin{array}{l}5 \text { min } \\
\text { holding }\end{array}$ & 200 & 110 & $\begin{array}{l}\text { Open } \\
\text { the } \\
\text { furnace } \\
\text { door }\end{array}$ \\
\hline
\end{tabular}

\subsection{Characterization}

Rectangular bar specimens of size $3 \times 4 \times 36 \mathrm{~mm}^{3}$ were used for mechanical properties and TSR tests, as shown in Fig. 1. The bars were ground with a diamond wheel and polished using diamond pastes to a $R a$ of $\sim 0.1 \mu \mathrm{m}$. Three-point-bending was used to measure the flexural strength on an electronic universal experimental instrument (WD-10, produced by Jinan TEST Co., Ltd. P.R. China) with a span of $20 \mathrm{~mm}$ at a crosshead speed of $0.5 \mathrm{~mm} \mathrm{~min}^{-1}$. Six specimens with the same compositions were used for measuring the flexural strength in air at room temperature.

The flexural strength was calculated by the following formula [37]:

$$
\sigma_{f}=\frac{3 P L}{2 b h^{2}}
$$


where $\sigma_{\mathrm{f}}$ was flexural strength $(\mathrm{MPa})$ and $P$ was load $(\mathrm{N})$ under which the samples broke, $b$ and $h$ were width and height $(\mathrm{mm})$, respectively, and $L$ was span $(\mathrm{mm})$.

Vickers hardness was measured on polished surfaces with a load of $9.8 \mathrm{~N}$ for $5 \mathrm{~s}$ with a micro-hardness tester (MH-6). Indentation fracture resistance measurement was performed using the indentation method with a hardness tester ( $\mathrm{Hv}-120$, produced by Shanghai Hengyi electronic testing instrument corporation, P.R. China), and results were obtained by the formula proposed by Cook and Lawn [38]. Five indents were made in a row at the middle of each specimen to obtain an average value. XRD ( $/$ max-2400) analysis was adopted to identify the phases after sintering. Microstructures of the samples were studied on fracture surfaces by scanning electron microscopy (SEM, HITACHI S-570, produced by Japan Hitachi Co., Ltd.).

Ground and polished rectangular bars for thermal shock testing were placed into a furnace and heated to the desired temperatures at a heating rate of $20^{\circ} \mathrm{C} / \mathrm{min}$. After the specimens were heated for $30 \mathrm{~min}$ in the furnace to induce the homogeneous temperature distribution, they were dropped into a bath of water at room temperature. $\Delta T$, the temperature differences for all composites were chosen referring to literature [35, 38-41]. The experiment temperature differences are $200,300,400,500$ and $600^{\circ} \mathrm{C}$, respectively. The flexural strengths of the specimens after thermal shock at each temperature were also measured by three-point-bending method. The results were the average value of a minimum number of six specimens tested in the same condition. The surface of the specimens after thermal shock examined by the same SEM equipment with that of before thermal shock tests.

\section{Results And Discussion}

\subsection{Mathematics model of temperature gradient spark plasma sintering}

The spline interpolation feature points, as listed in Table 3, were obtained according to the given conditions listed in Table 2.

Table 3

The spline interpolation feature points during the sintering process

\begin{tabular}{|lll|}
\hline$\left(t_{0}, T_{0}\right)=(0,20)$ & $\left(t_{1}, T_{1}\right)=(4.5,700)$ & $\left(t_{2}, T_{2}\right)=(8.3,1000)$ \\
\hline$\left(t_{3}, T_{3}\right)=(14,1350)$ & $\left(t_{4}, T_{4}\right)=(19,1350)$ & $\left(t_{5}, T_{5}\right)=(21,1000)$ \\
& $\left(t_{6}, T_{6}\right)=(30,50)$ & \\
\hline
\end{tabular}

where $T$ represented the sintering temperature and $t$ was the sintering time. The sintering temperature changed evenly as time went in each temperature interval. The functional relation of temperature and time was as follows: 


$$
T(t)=\frac{t_{\mathrm{i}+1}-t}{t_{\mathrm{i}+1}-t_{\mathrm{i}}} T_{\mathrm{i}}+\frac{t_{\mathrm{i}}-t}{t_{\mathrm{i}}-t_{\mathrm{i}+1}} T_{\mathrm{i}+1} \quad t \in\left[t_{\mathrm{i}}, t_{\mathrm{i}+1}\right]
$$

where $T_{\mathrm{i}}$ and $T_{\mathrm{i}+1}$ represented the sintering temperature at $i$ and $i+1 . t_{\mathrm{i}}$ and $t_{\mathrm{i}+1}$ represented the sintering time at $i$ and $i+1$. It was indicated that the relationship between sintering temperature and time was a linear interpolating function of subsection splines, and it was a line chart. The sintering temperature was raised or reduced constantly in every temperature interval and the rising of whole temperature was decelerated. It spent approximately $30 \mathrm{~min}$ in the whole SPS process, in which 5 min holding time was used.

\subsection{X-ray diffraction phase analysis}

The X-ray diffraction phase analysis of sample AOT4 is shown in Fig. 2. It was clear that there existed $\mathrm{Al}_{2} \mathrm{O}_{3}, \mathrm{SiO}_{2}$ and $\mathrm{Ca}_{3} \mathrm{SiO}_{5}$ phases in sample AOT4. The following chemical reaction, yielding $\mathrm{Ca}_{3} \mathrm{SiO}_{5}$, may occur during the sintering process:

$3 \mathrm{CaO}+\mathrm{SiO}_{2} \rightarrow \mathrm{Ca}_{3} \mathrm{SiO}_{5}(3)$

The Gibbs free energy, of reaction (3) was $-162 \mathrm{KJ}$ at the temperature of $1350^{\circ} \mathrm{C}$, which indicated that reaction (3) was possible to take place based on thermodynamic analysis. X-ray diffraction phase analysis of sample AOT4 confirmed reaction (3).

\subsection{Mechanical properties}

The mechanical properties of TGSPS sintered alumina composites are listed in Table 1. Vickers hardness, fracture toughness and flexural strength of pure alumina (sample PAO) was $17.6 \mathrm{GPa}, 4.65 \mathrm{MPa} \cdot \mathrm{m}^{1 / 2}$ and 391.6 MPa, respectively. Addition of tremolite significantly improved the performances of TGSPS sintered composites, whose Vickers hardness, fracture toughness and flexural strength reached their maximum value of $20.1 \mathrm{GPa}, 4.77 \mathrm{MPa} \cdot \mathrm{m}^{1 / 2}$ and $538.2 \mathrm{MPa}$, respectively. The hardness and toughness of the composites increased with increasing tremolite content from 2 to $4 \mathrm{wt} . \%$, and then decreased from 4 to $8 \mathrm{wt} . \%$. There were two factors influencing the hardness of composites, namely a hardness effect due to the addition of tremolite and a densification effect of the composites. In the first stage (2 to $4 \mathrm{wt} . \%$ addition), the densification effect was dominant and the hardness was enhanced, while the hardness was reduced as the hardness effect was in turn becoming dominant (4 to $8 \mathrm{wt} . \%$ addition) for the reason that the hardness of tremolite were lower than that of alumina. Fracture toughness increased with increasing the amount of tremolite before $4 \mathrm{wt} . \%$, at which point it reached the maximum value of $4.77 \mathrm{MPa} \cdot \mathrm{m}^{1 / 2}$, and then decreased after $4 \mathrm{wt} . \%$. Flexural strength reached its maximum value for sample AOT 6 with 6 wt.\% tremolite addition and then decreased for further tremolite addition. This trend of flexural strength correlated with the microstructures of the composites, which would be discussed in Sect. 3.5. 
It was obvious that the TGSPS sintered alumina composites exhibited significant improvement in mechanical properties. Composite with an addition of $4 \mathrm{wt} . \%$ tremolite showed excellent mechanical properties, the hardness, fracture toughness and flexural strength of the composite were enhanced by $14.2 \%, 2.6 \%$ and $28.6 \%$, respectively, with respect to sample PAO sintered under the same conditions.

\subsection{Thermal shock resistance}

Figure 3 shows a plot of residual flexural strengths versus temperature difference $(\Delta T)$ for alumina composites after the water-quenching tests. A three-stage behavior of flexural strength, which is coincidence with the Hasselman's theory, was presented, and all the samples exhibited a drastic reduction in flexural strength compared with their initial strengths. The residual strength of sample PAO was lower than that of sample AOT4 and AOT6 through the entire range. The curve for sample PAO showed a critical temperature difference $\left(\Delta T_{\mathrm{c}}\right)$ of $320^{\circ} \mathrm{C}$ and the characteristic sharp loss of flexural strength at the point, followed by a gradual decrease for further increasing. $\Delta T_{\mathrm{C}}$ of sample AOT4 and AOT6 was 372 and $360{ }^{\circ} \mathrm{C}$, respectively. Sample of AOT4 and AOT6 showed appreciably greater $\Delta T_{\mathrm{C}}$ and residual strength after $\triangle T_{\mathrm{C}}$ than sample PAO. The results demonstrated that the addition of tremolite in alumina modified the composites mechanical properties and, hence improved the thermal shock behaviours.

\subsection{Analysis of microstructures}

SEM photomicrographs of fracture surface of samples PAO, AOT4 and AOT6 are shown in Fig. 4. The grain boundaries of sample PAO were unobservable and the fracture mode was mainly transgranular. There existed apparent pores (marked with arrow in Fig. 4a) on the fracture surface of sample PAO. Pores in samples AOT4 and AOT6, however, were much fewer than that in sample PAO, which showed that the addition of tremolite decreased the amount of pores in TGSPS sintered alumina composites. The eliminating of porosities contributed to a certain extent enhanced flexural strength of samples AOT4 and AOT6. The sintering temperature was $1350^{\circ} \mathrm{C}$, which was higher than the melting point of tremolite, liquid phase might appeare in the TGSPS process. The eliminating of porosities might be mainly due to the smooth flowing of liquid phases, which was formed by tremolite. There were some smaller grains formed in the crystal boundaries for sample AOT4 (circled in Fig. 4b). These small particles formed in a typical intergranular fracture mode, extending the path of crack growth, and contributed to the improvement of fracture toughness for sample AOT4. The fracture surfaces of sample AOT6 (Fig. 4c) were relatively rough and presented brittle character. As was previously discussed in Sect. 3.2, during the TGSPS process, interface reaction took place among $\mathrm{CaO}$ and $\mathrm{SiO}_{2}$ to yield $\mathrm{Ca}_{3} \mathrm{SiO}_{5}$, existed on the crystal boundaries of alumina composites, strengthened the grain boundaries of the composites, and as a result, contributed to the improvement in flexural strength of alumina composites.

The effect of porosity on mechanical properties is as follows: $[42,43]$

$M_{\mathrm{p}}=M_{\mathrm{p} 0} \exp \left(-b V_{\mathrm{fp}}\right)(4)$ 
Where $M_{\mathrm{p}}$ was the mechanical property, $V_{\mathrm{fp}}$ was the volume fraction of porosity, $b$ was an empirical constant and the subscript 0 indicated zero porosity. The following Eq. (5) could be concluded from Eq. (4):

$$
R=\sigma_{0} \exp \frac{\left(-b_{\sigma} V_{\text {๓ई }}\right)(1-v)}{\alpha E_{0} \exp \left(-b_{E} V_{\text {ईp }}\right)}
$$

Where $R$ represented the thermal shock parameters, $b_{\sigma}$ and $b_{\mathrm{E}}$ was empirical constant for the flexural strength and Young modulus of alumina composites, respectively. Usually $b_{\mathrm{E}}<b_{\sigma}$ [44-46], so the higher the $V_{\mathrm{fp}}$ is, the lower the $R$ is, and the poorer the TSR of composites will be. There were some pores existed in the fracture surface of sample PAO (Fig. 4a), fewer pores were found in the fracture surfaces of sample AOT4 and AOT6 (Fig. 4b and c), indicating that the improved TSR was obtained for sample AOT4 and AOT6 comparing with sample PAO. It was concluded that the addition of tremolite could promote the liquid phases sintering of alumina composites, decrease the porosity, strength the grain boundaries, improve the mechanical properties, and thus contribute to the improvement in TSR of alumina composites.

Figure 5 indicates the schematic of the mechanisms of interactions between the crack and particles. Comparing Fig. $5 a$ with $b$, one could find that the difference in the opening displacement of crack tip between different sizes of grains when the crack propagated the interface between different sizes of grains (Fig. 5b), which would result in the fact that the crack propagated along the big grain. This meant that the crack was locally blunted, and the propagation length of the crack was extended, which contributed to the improvement of fracture toughness for sample AOT4.

The fracture surface morphologies of alumina composites at $\Delta T=400{ }^{\circ} \mathrm{C}$ are presented in Fig. 6 . A flat fracture surface was found for sample PAO at $\Delta T=400^{\circ} \mathrm{C}$, and the sample remained the transgranular fracture type. The flatter and large size cleavages extended over the entire fracture surfaces, indicating that the cracks propagated fairly easy across sample PAO without crack deflections like Fig. $5 \mathrm{a}$, and the cracks penetrated the alumina particles at $\Delta T=400^{\circ} \mathrm{C}$ (Fig. 6a) without appreciable resistance, giving rise to great drops in its residual strengths, which could explain the poor TSR of sample PAO. The enhancement of the residual strength of the alumina composites was attributed to the microstructure evolution of composites after thermal shock, and the microstructure of the samples after the quenching test provided an insight on the important details of thermal shock behavior. The fracture surface of sample AOT4 and AOT6 at $\Delta T=400{ }^{\circ} \mathrm{C}$ (Fig. $6 \mathrm{~b}$ and $\mathrm{c}$ ) showed a relatively rough surface with a fracture mode of the combination of intergranular and transgranular failure. Dimple with a characteristic of ductile fracture could be obviously observed in Fig. 6b (marked with arrow), showing the pullout of alumina grains and indicating the high residual flexural strength of sample AOT4 at $\Delta T=400{ }^{\circ} \mathrm{C}$. Transgranular cleavage was found in the fracture surface of sample AOT6 (marked with arrow in Fig. 6c), indicating a relative lower residual flexural strength of sample AOT6 than that of AOT4. 
The alumina composites were sintered to a high densification rate (Table 1) and there remained few pores in alumina composite, which enhanced the resistance to the crack initiation and load-bearing capacity of alumina composites. The compact structure of alumina composites led to a better flexural strength of alumina composite. Sample AOT6 has the higher initial flexural strength (538.2 MPa) than sample AOT4 (503.5 MPa), According to the theory of thermal shock fracture, sample AOT6 was more resistant to crack initiation. However, its $\Delta T_{\mathrm{C}}$ was lower than that of sample AOT4. Sample AOT4 has the higher initial fracture toughness (4.77 MPa. $\mathrm{m}^{1 / 2}$ ) than sample AOT6 $\left(4.15 \mathrm{MPa} \cdot \mathrm{m}^{1 / 2}\right)$, which meant sample AOT4 possessed higher resistance to crack propagation. It was confirmed that the crack propagation rather than crack initiation dominated TSR in current composite ceramic system. It is well known that the flexural strength and fracture toughness are the most important factors to influence the TSR of ceramics [47-50]. The TSR of composites could be assessed by using the critical crack length, $L_{c}$, as follows [49]:

$$
L_{C}=\frac{K_{\mathrm{IC}}^{2}}{\pi \times \sigma_{\mathrm{f}}}
$$

where $K_{\mathrm{IC}}$ was the fracture toughness of the composites. The improvement of $L_{C}$ contributed to the enhanced TSR of alumina composites. Sample AOT4 had the higher $L_{C}$ value $(0.014)$ than that of sample AOT6 (0.01), which could explain the improvement in the TSR of sample AOT4.

\section{Conclusion}

Alumina composites were fabricated by TGSPS technology. The mathematics model of TGSPS was established using piecewise interpolation spline function. The following conclusions were obtained:

1. The relationship between sintering temperature and time was a linear interpolating function of subsection splines.

2. Composite with an addition of $4 \mathrm{wt} . \%$ tremolite showed excellent mechanical properties, the Vickers hardness, fracture toughness and flexural strength of the composite were $20.1 \mathrm{GPa}, 4.77 \mathrm{MPa} \cdot \mathrm{m}^{1 / 2}$ and $503.5 \mathrm{MPa}$, respectively.

3. Liquid phase sintering occurred in the TGSPS process, the smooth flowing of liquid phases contributed to the eliminating of porosities, which led to improved mechanical properties of the alumina composites.

4. The improved TSR was attributed to increased fracture toughness by moderate tremolite addition and the eliminating of porosity

\section{Declarations}

\section{Acknowledgements}


The authors are grateful for financial support from the National Natural Science Foundation of China (Grant Nos. 51505208), Key Technology Research and Development Program of Shandong province (Grant No. 2019GGX104085), Natural Science Fund project in Shandong province (Grant No. ZR2018PEE010) and Scientific Research Projects in University of Shandong province (Grant No. J18KA031).

\section{References}

1. Zhongliang Lu (2016) GuoqiangTian, WeijianWan, KaiMiao, DichenLi. Effect of in situ synthesized mullite whiskers on the high-temperature strength of $\mathrm{Al}_{2} \mathrm{O}_{3}$-based ceramic moulds for casting hollow turbine blades. Ceram Int 42:18851-18858

2. Deng Jianxin L, Lili L, Jianhua Z, Jinlong $Y$ (2005) Xuefeng. Failure mechanisms of $\mathrm{TiB}_{2}$ particle and $\mathrm{SiC}$ whisker reinforced $\mathrm{Al}_{2} \mathrm{O}_{3}$ ceramic cutting tools when machining nickel-based alloys. Int $\mathrm{J}$ Mach Tools Manuf 45(12-13):1393-1401

3. Yin Z, Huang C, Yuan J, Zou B, Liu H, Zhu H. Cutting performance and life prediction of an $\mathrm{Al}_{2} \mathrm{O}_{3} / \mathrm{TiC}$ micro-nano-composite ceramic tool when machining austenitic stainless steel, Ceramics International, 41(5)Part B(2015)7059-7065

4. Deng Jianxin $Y$, Dongling $T$ Yuanqiang. Design, fabrication and performance of $\mathrm{Al}_{2} \mathrm{O}_{3} /\left(\mathrm{W}_{0.7} \mathrm{Ti}_{0.3}\right) \mathrm{C}+$ $\mathrm{Al}_{2} \mathrm{O}_{3} / \mathrm{TiC}$ multilayered ceramic nozzles, International Journal of Refractory Metals and Hard Materials, 27 (4) (2009) 734-739

5. Deng Jianxin F, Yihua D, Zeliang S, Peiwei (2003) Wear behavior of ceramic nozzles in sand blasting treatments. J Eur Ceram Soc 23(2):323-329

6. Walker WJ Jr, (Toledo OH, US). Spark plug having a ceramic insulator with improved high temperature electrical properties, United States Patent 7799717, Publication Date: 09/21/2010

7. Carpio P, Salvador MD, Borrell A, Sánchez E, Moreno R. Alumina-zirconia coatings obtained by suspension plasma spraying from highly concentrated aqueous suspensions, Surface and Coatings Technology, 307(Part A)(2016)713-719

8. Mirzamohammadi S, Khorsand H, Aliofkhazraei M (2017) Effect of different organic solvents on electrodeposition and wear behavior of Ni-alumina nanocomposite coatings. Surface Coatings Technology 313:202-213

9. Karim Hentour A, Marsal V, Turq et al (2016) Carbon nanotube/alumina and graphite/alumina composite coatings on stainless steel for tribological applications. Materials Today Communications 8:118-126

10. Sonny Bal B, Rahaman MN (2011) Alumina Ceramic Bearings in Total Hip Arthroplasty: The Rationale for Patient Selection. Seminars in Arthroplasty 22(4):254-257

11. Tomaž Kosmač

Corrado Piconi SG, Condo, Tomaž Kosmač. Chapter 11 - Alumina- and Zirconia-based Ceramics for Load-bearing Applications, Advanced Ceramics for Dentistry, (2014) 219-253 
12. Jiangyuan F, Lin T, Hu F, Ibrahim YYu,M, Zheng R, Huang S, Ma J (2017) Effect of sintering temperature on microstructure and mechanical properties of zirconia-toughened alumina machinable dental ceramics. Ceram Int 43(4):3647-3653

13. Tingting Wu B, Wu S, Zhao (2013) Acid resistance of silicon-free ceramic proppant. Mater Lett 92:210-212

14. Bennison SJ, Harmer MP (1983) Effect of $\mathrm{MgO}$ solute on the kinetics of grain growth in $\mathrm{Al}_{2} \mathrm{O}_{3}$. J Am Ceram Soc 66(5):C90-C92

15. Berry KA (1986) and M. P.Harmer. Effect of $\mathrm{MgO}$ solute on microstructure development in $\mathrm{Al}_{2} \mathrm{O}_{3} . \mathrm{J}$ Am Ceram Soc 69(2):143-149

16. Bennison SJ, Harmer MP (1990) Effect of magnesia solute on surface diffusion in sapphire and the role of magnesia in the sintering of alumina. J Am Ceram Soc 73(4):833-837

17. Baik S, Moon JH (1991) Effect of magnesium oxide on grain-boundary segregation of calcium during sintering of alumina. J Am Ceram Soc 74(4):819-822

18. Bae SI, Baik S (1994) Critical concentration of $\mathrm{MgO}$ for the prevention of abnormal grain growth in alumina. J Am Ceram Soc 77(10):2499-2504

19. Azhar AZA, Mohamed H, Ratnam MM, Ahmad ZA (2010) The effects of MgO addition on microstructure, mechanical properties and wear performance of zirconia-toughened-alumina (ZTA) cutting inserts. Journal of Alloys Compounds 497:316-320

20. Rittidech A, Portia L, Bongkarn T (1998) The relationship between microstructure and mechanical properties of $\mathrm{Al}_{2} \mathrm{O}_{3}-\mathrm{MgO}$ ceramics. Materials Science Engineering: A 38(5):2305-2316

21. Nakajima A, Messing GL (1996) Liquid-phase sintering of alumina coated with magnesium aluminosilicate glass. J Am Ceram Soc 79(12):3199-3210

22. Mihye Kong T, Vogt $Y$, Lee (2018) High-pressure synchrotron $X$-ray diffraction study of tremolite and actinolite in various fluids. Curr Appl Phys 18(11):1218-1224

23. Guyot P, Antou G, Pradeilles $N$ et al (2014) Hot pressing and spark plasma sintering of alumina: Discussion about an analytical modelling used for sintering mechanism determination. Scripta Mater 84-85:35-38

24. Trunec M, Klimke J (2016) Zhijian James Shen. Transparent alumina ceramics densified by a combinational approach of spark plasma sintering and hot isostatic pressing. J Eur Ceram Soc 36(16):4333-4337

25. Qin Y, Liu J-X, Li F, Wei X, Wu H (2019) Guo-Jun Zhang. A high entropy silicide by reactive spark plasma sintering. Journal of Advanced Ceramics 8:148-152

26. Gao L, Wang HZ, Hong JS et al (1999) Mechanical properties and microstructure of nano $\mathrm{SiC}^{-\mathrm{Al}_{2} \mathrm{O}_{3}}$ composites densified by spark plasma sintering. J Eur Ceram Soc 19:609-613

27. Zhang J, Tu R, Goto T (2014) Spark plasma sintering of $\mathrm{Al}_{2} \mathrm{O}_{3}$-Ni nanocomposites using $\mathrm{Ni}$ nanoparticlesproduced by rotary chemical vapour deposition. J Eur Ceram Soc 34:435-441 
28. Ozden Ormanci I, Akin F, Sahin et al (2014) Spark plasma sintered $\mathrm{Al}_{2} \mathrm{O}_{3}-\mathrm{YSZ}-\mathrm{TiO}_{2}$ composites: Processing, characterization and in vivo evaluation. Mater Sci Eng C 40:16-23

29. Chen W-H, Lin H-T, Chen J et al (2016) Microstructure and wear behavior of spark plasma sintering sintered $\mathrm{Al}_{2} \mathrm{O}_{3} /$ WC-based composite. Int Journal of Refractory Metals Hard Materials 54:279-283

30. Jinling Liu Y, Wang F, Yang et al (2015) Grain refining in spark plasma sintering $\mathrm{Al}_{2} \mathrm{O}_{3}$ ceramics. $J$ Alloy Compd 622:596-600

31. Lao X, Xu X, Cheng H et al (2019) Effect of rare-earth oxides on microstructure and thermal shock resistance of $\mathrm{Al}_{2} \mathrm{O}_{3}$-SiCW composite ceramics for solar thermal storage. Ceram Int 45:2003-2011

32. Junjie Song Y, Su H (2017) Fan, et al. A novel design to produce high-strength and high-toughness alumina self-lubricated composites with enhanced thermal-shock resistance-Part I: Mechanical properties and thermal shock behavior of $\mathrm{Al}_{2} \mathrm{O}_{3} / \mathrm{Mo}-\mathrm{Al}_{2} \mathrm{O}_{3}$ laminated composites. $\mathrm{J}$ Eur Ceram Soc 37:213-221

33. leva Zake-Tiluga, Svinka V, RutaSvinka, et al. Thermal shock resistance of porous $\mathrm{Al}_{2} \mathrm{O}_{3}$-mullite ceramics, Ceram Int, 41(2015)11504-11509

34. Ying Nie PB, Oliete, Rosa I, Merino (2019) Influence of microstructural size on the thermal shock behavior of $\mathrm{Al}_{2} \mathrm{O}_{3}-\mathrm{Er}_{3} \mathrm{Al}_{5} \mathrm{O}_{12}$ directionally solidified eutectics. Scripta Mater 160:20-24

35. Changxia Liu J, Sun FengGong et al (2020) Effects of micro and macro features on the thermal shock resistance of laminated $\mathrm{Al}_{2} \mathrm{O}_{3}-\mathrm{MgO}$ composites. Ceram Int 46(7):9606-9613

36. Pettersson P, Johnsson M, Shen Z (2002) J Eur Ceram Soc 22:1883-1889

37. Changxia Liu J, Sun G, Li B, Li (2020) FengGong. Fabrication, mechanical properties and fracture behaviors of the laminated $\mathrm{Al}_{2} \mathrm{O}_{3}-\mathrm{ZrB}_{2}-\mathrm{MgO} / \mathrm{Al}_{2} \mathrm{O}_{3}-\mathrm{TiN}-\mathrm{MgO}$ ceramic composite. Ceram Int 46(1):857-865

38. Cook RF, Lawn BR (1983) A modified indentation toughness technique. J Am Ceram Soc 66(11):200-201

39. Zhao J, Ai X, Huang XP (2002) Relationship between the thermal shock behavior and the cutting performance of a functionally gradient ceramic tool. Journal of Materials Processing Tech 129:161166

40. Maensiri S, Roberts SG (2002) Thermal shock of ground and polished alumina and $\mathrm{Al}_{2} \mathrm{O}_{3} / \mathrm{SiC}$ nanocomposites. J Eur Ceram Soc 22:2945-2956

41. Wang L, Shi JL (2001) Influence of tungsten carbide particles on resistance of alumina matrix ceramics to thermal shock. J Eur Ceram Soc 21:1213-1217

42. Duckworth W (1953) Discussion of Ryshkewitch paper by Winston Duckworth. J Am Ceram Soc $36: 68$

43. E.Ryshkewitch (1953) Compression strength of porous sintered alumina and zirconia. J Am Ceram Soc 36:65-68

44. Rice RW. Porosity of Ceramics, Marcel Dekker, ISBN:0-8247-0151-8, 1998 
45. Chen Y. Thermal Shock Behavior of Ceramics with Porous and Layered Structures, Ph.D. Thesis, University of Cambridge, 1999

46. Dorey RA, Yeomans JA, Smith PA (2002) Effect of pore clustering on the mechanical properties of ceramics. J Eur Ceram Soc 22:403-409

47. Ziegler G (1983) Progress in nitrogen ceramics. Martinus Nihoff Publisher, Boston, pp 565-588

48. Hirano $\mathrm{T}$, Niihara $\mathrm{K}$ (1996) Thermal shock resistance of $\mathrm{Si}_{3} \mathrm{~N}_{4} / \mathrm{SiC}$ nanocomposites fabricated from amorphous $\mathrm{Si}-\mathrm{C}-\mathrm{N}$ precursor powders. Materials Letter 26:285-289

49. Cui K, Li Y (2016) Fabrication, mechanical properties and thermal shock resistance of laminated $\mathrm{TiB}_{2}$-based ceramic. International Journal of Refractory Metals Hard Materials 54:148-153

50. Ning Liao D, Jia Z, Yang Yu (2019) Zhou. Enhanced mechanical properties and thermal shock resistance of $\mathrm{Si}_{2} \mathrm{BC}_{3} \mathrm{~N}$ ceramics with $\mathrm{SiC}$ coated MWCNTs. Journal of Advanced Ceramics 8:121132

\section{Figures}

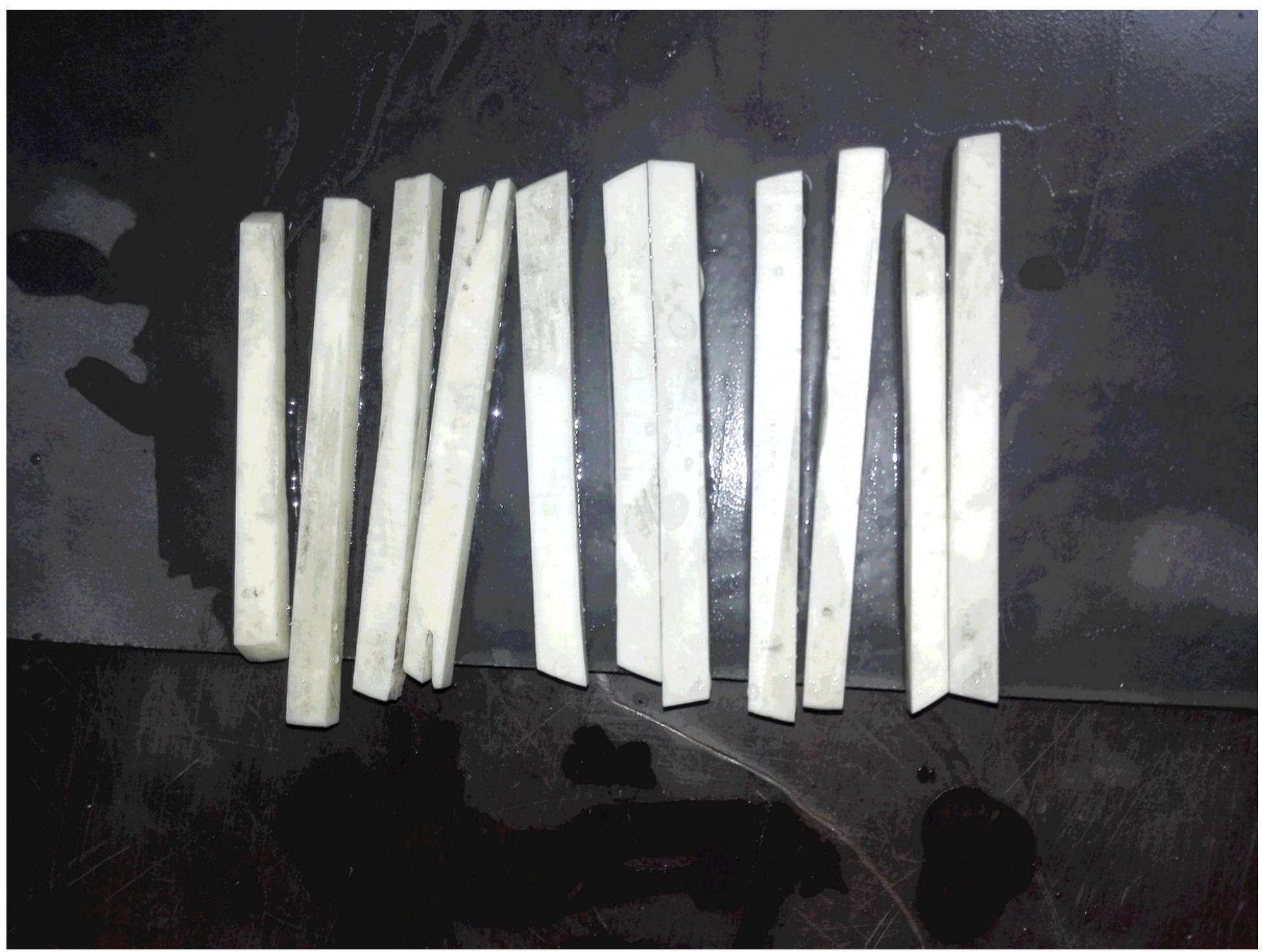


Figure 1

Standard test pieces $(3 \times 4 \times 36 \mathrm{~mm} 3)$ for measuring mechanical properties and TSR tests

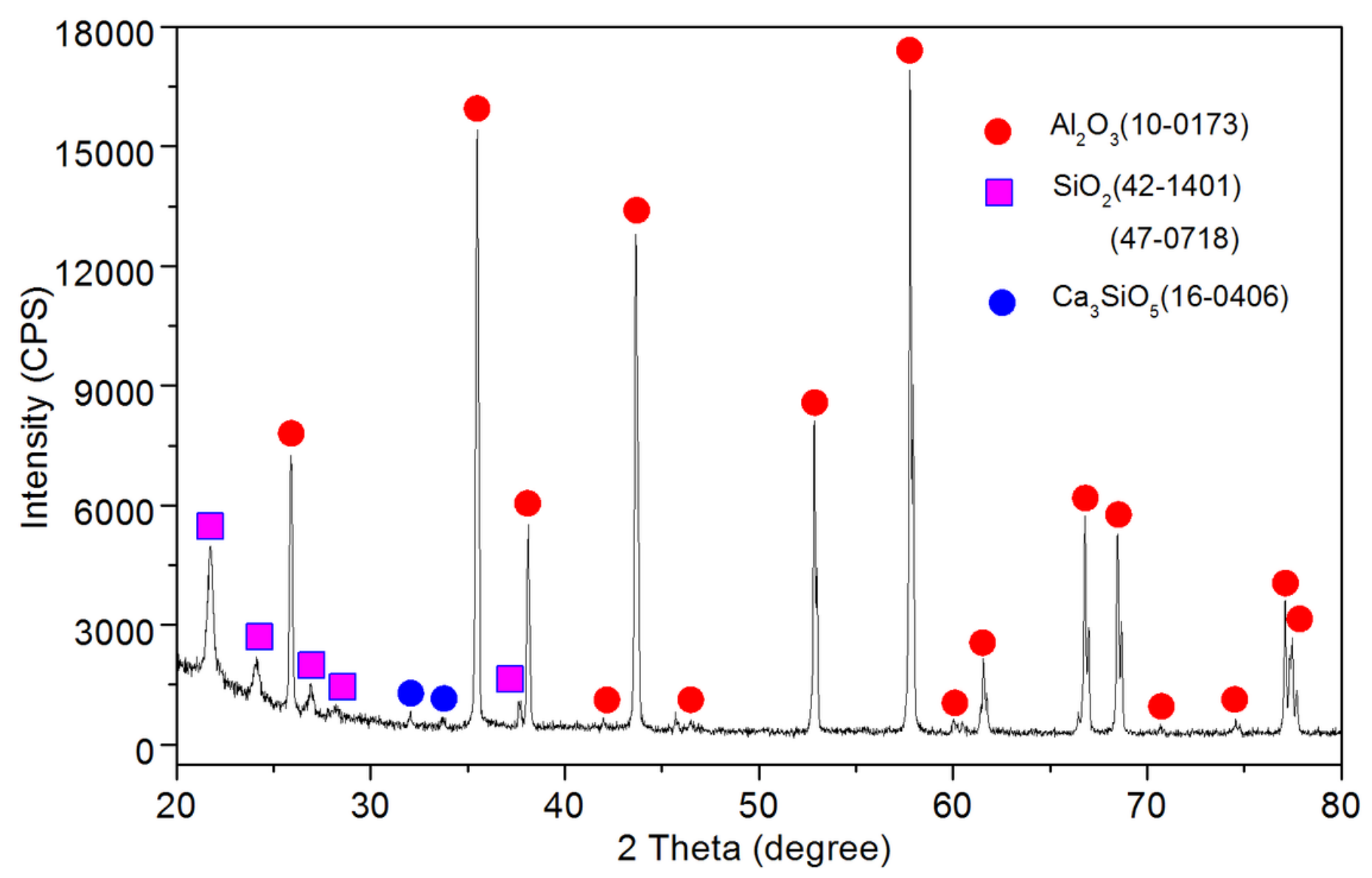

Figure 2

X-ray diffraction phase analysis of sample AOT4 


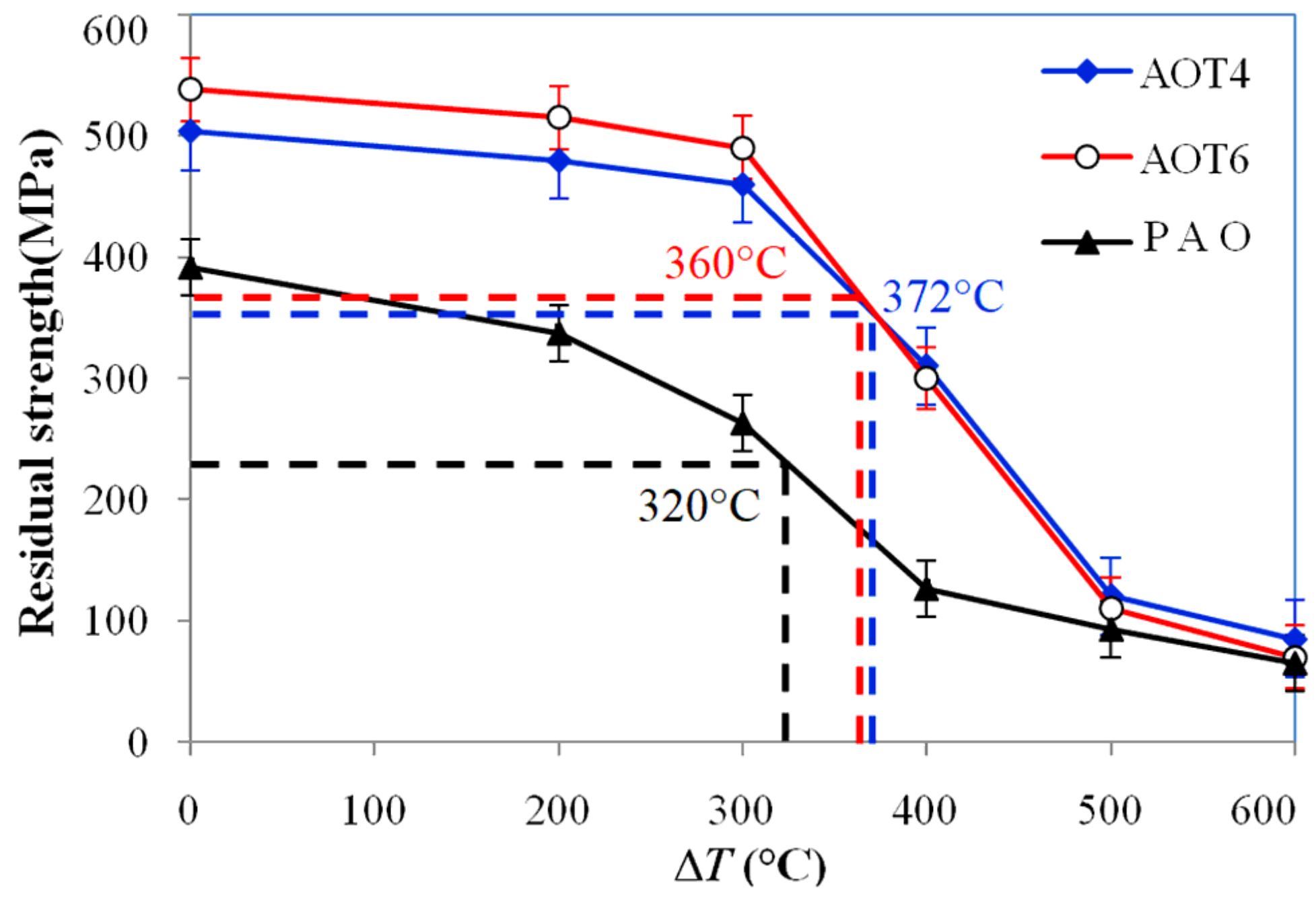

Figure 3

Residual flexural strength of alumina composites at different thermal shock temperature difference, $\Delta \mathrm{T}$, for single thermal shock 


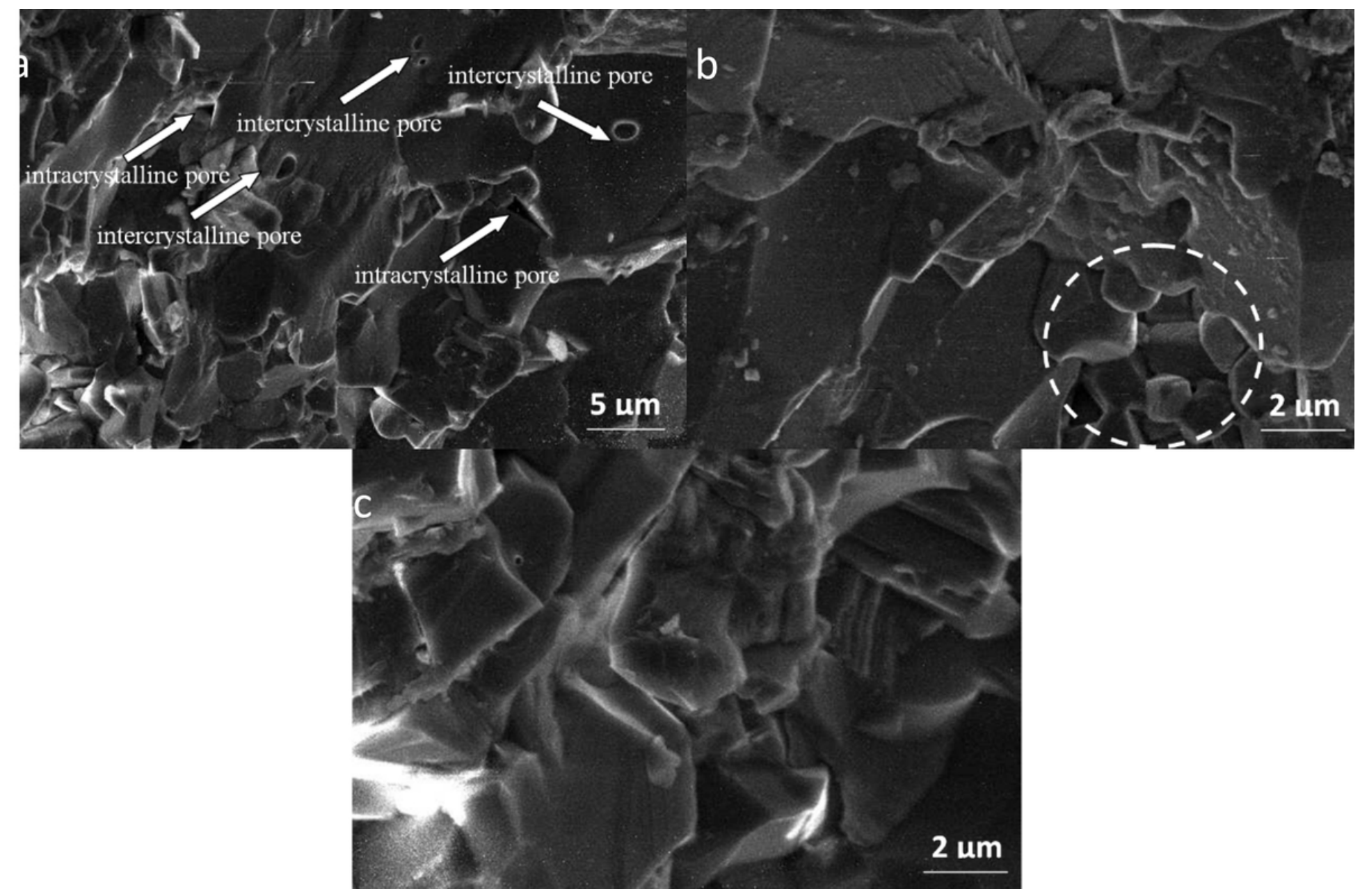

Figure 4

SEM photomicrograph on fracture surface of alumina composites (a) PAO; (b) AOT4; (c) AOT6
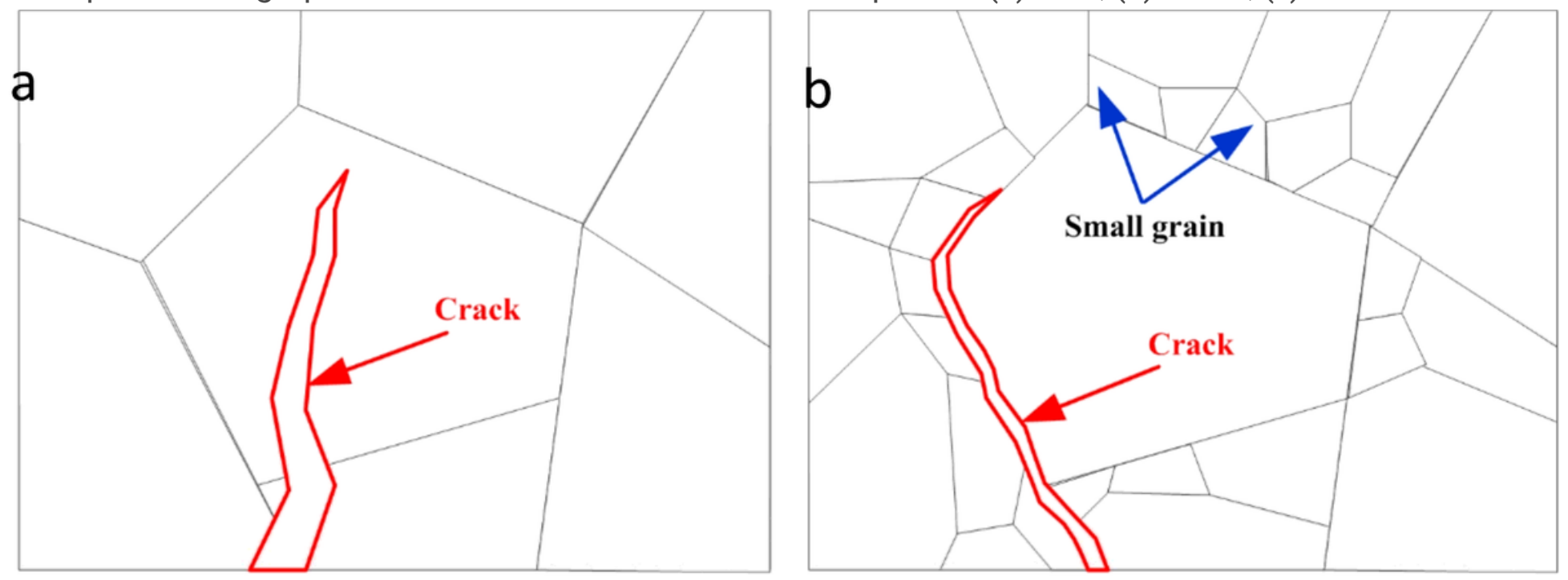

\section{Figure 5}

Schematic of the mechanisms of interactions between the crack and particles (a) crack propagated through the alumina grains; (b) crack propagated along the grain boundaries of the alumina particles 

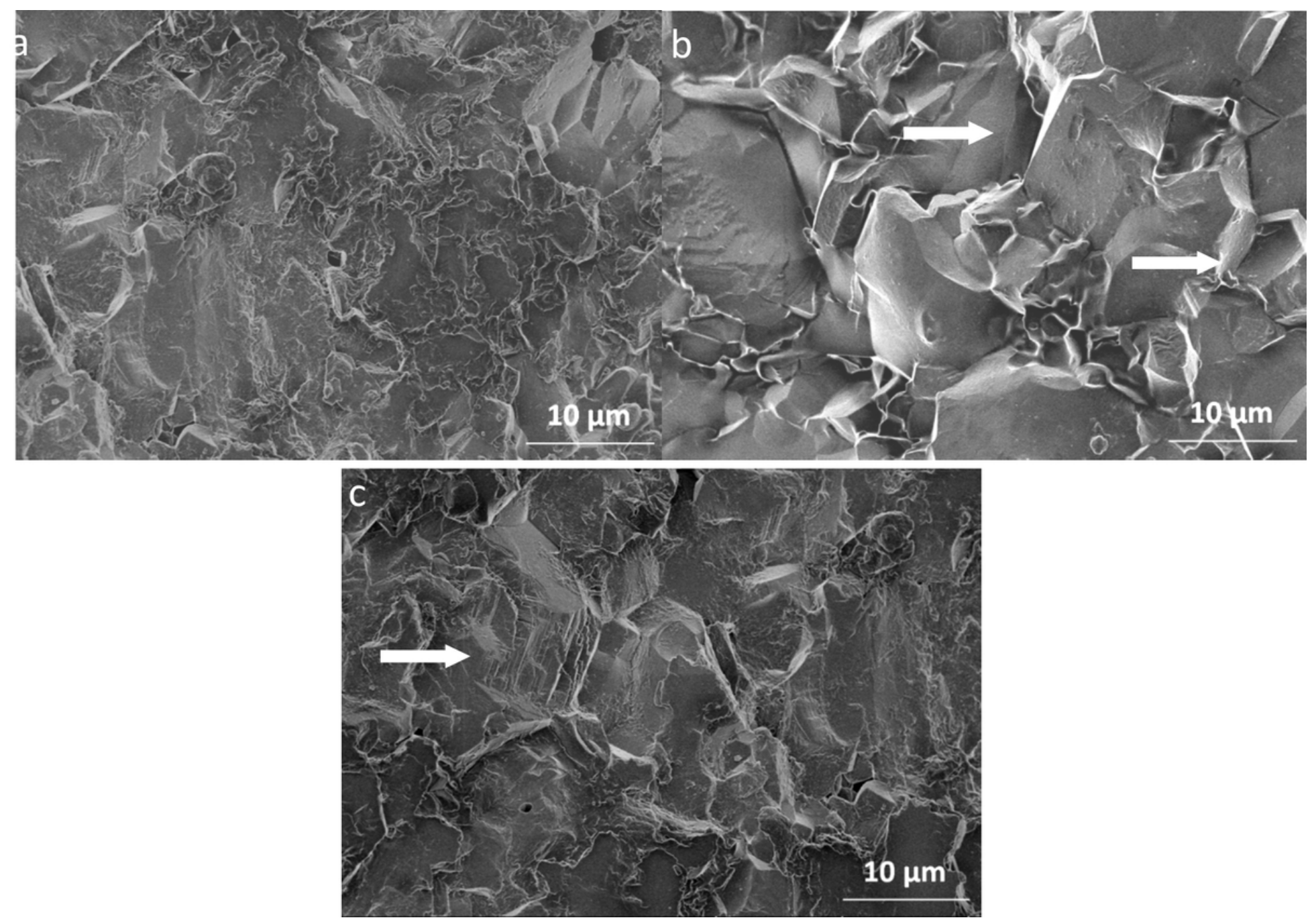

Figure 6

Fracture surface morphologies of alumina composites after $\Delta T=400^{\circ} \mathrm{C}$ (a) PAO; (b) AOT4; (c) AOT6 